Masterclass

\title{
How to manage patellofemoral pain - Understanding the multifactorial nature and treatment options
}

\author{
Simon Lack ${ }^{\text {a, b, * }}$, Bradley Neal a, b, Danilo De Oliveira Silva ${ }^{\text {c, d }}$, Christian Barton ${ }^{\text {a, c }}$ \\ a Sports and Exercise Medicine, William Harvey Research Institute, School of Medicine and Dentistry, Queen Mary University London, London, United \\ Kingdom \\ ${ }^{\mathrm{b}}$ Pure Sports Medicine, London, United Kingdom \\ ' Sport and Exercise Medicine Research Centre, School of Allied Health, La Trobe University, Melbourne, Australia \\ d Laboratory of Biomechanics and Motor Control, Sao Paulo State University (UNESP), Presidente Prudente, Brazil
}

\section{A R T I C L E I N F O}

\section{Article history:}

Received 18 December 2017

Received in revised form

11 April 2018

Accepted 11 April 2018

\section{Keywords:}

Patellofemoral pain

Rehabilitation

Biomechanics

Education

\begin{abstract}
A B S T R A C T
Patellofemoral pain (PFP) is one of the most prevalent conditions within sports medicine, orthopaedic and general practice settings. Long-term treatment outcomes are poor, with estimates that more than $50 \%$ of people with the condition will report symptoms beyond 5 years following diagnosis. Additionally, emerging evidence indicates that PFP may be on a continuum with patellofemoral osteoarthritis. Consensus of world leading clinicians and academics highlights the potential benefit of delivering tailored interventions, specific to an individual's needs, to improve patient outcome. This clinical masterclass aims to develop the reader's understanding of PFP aetiology, inform clinical assessment and increase knowledge regarding individually tailored treatment approaches. It offers practical application guidance, and additional resources, that can positively impact clinical practice.
\end{abstract}

() 2018 Elsevier Ltd. All rights reserved.

\section{Introduction}

Patellofemoral pain (PFP) is one of the most prevalent conditions within sports medicine, orthopaedic and general practice settings (Baquie \& Brukner, 1997; Kannus, Aho, Jarvinen, \& Niittymaki, 1987; Taunton et al., 2002). The incidence of PFP varies significantly between specific populations, with figures as low as $3 \%$ in established runners and to as high as $43 \%$ in naval recruits during basic military training (Boling et al., 2009; Smith et al., 2018; Thijs, Van Tiggelen, Roosen, De Clercq, \& Witvrouw, 2007). In adolescents, the incidence of PFP has been reported to be as high as $10 \%$ in high school female athletes during the competitive basketball season (Myer et al., 2010). The variability in incidence and high prevalence within specific populations is indicative of a complex multifactorial condition and a lack of consensus on the most appropriate diagnostic criteria (Crossley, Stefanik, et al., 2016; Nunes, Stapait, Kirsten, Noronha, \& Santos, 2013).

Symptoms of PFP are characterised by pain around or behind the patella, aggravated by activities that increase load on the

\footnotetext{
* Corresponding author. Sports and Exercise Medicine, Mile End Hospital, Bancroft Road, London, E1 4DG, United Kingdom.

E-mail address: s.lack@qmul.ac.uk (S. Lack).
}

patellofemoral joint (PFJ) (e.g. squatting, ascending and descending stairs, prolonged sitting and running) (Collins, Vicenzino, van der Heijden, \& van Middelkoop, 2016; Crossley, Stefanik, et al., 2016). Individuals with PFP may also describe or experience crepitus emanating from the PFJ, tenderness on palpation of the patella facets and a small effusion (Crossley, Stefanik, et al., 2016). Although widely researched, the exact source of pain in people with PFP is unclear, with several theoretical models previously described (Dye, 2005; Sanchis-Alfonso, Rosello-Sastre, Monteagudo-Castro, \& Esquerdo, 1998). These include altered patellar tracking, resulting in elevated patellofemoral joint contact pressure ( $\mathrm{Ho}, \mathrm{Hu}$, Colletti, \& Powers, 2014; Powers, 2003), and a loss of tissue homeostasis in the surrounding innervated tissues including the synovial lining or fat pad (Dye, 2005).

Based on current evidence and clinical practice, exercise therapy forms the cornerstone of management for PFP (Crossley, Stefanik, et al., 2016; van der Heijden, Lankhorst, van Linschoten, BiermaZeinstra, \& van Middelkoop, 2015) with efficacy of a multimodal approach having been well reported (Barton, Lack, Hemmings, Tufail, \& Morrissey, 2015; Collins, Bisset, Crossley, \& Vicenzino, 2012). Despite the reported benefits of multimodal treatment for PFP, longer-term follow up data (5-20 years) indicates that more than $50 \%$ of individuals with PFP continue to experience symptoms 
and unfavourable outcomes (Lankhorst et al., 2016; Nimon, Murray, Sandow, \& Goodfellow, 1998; Witvrouw, Danneels, Van Tiggelen, Willems, \& Cambier, 2004). The development of a targeted intervention has been proposed to represent an approach that could positively impact long-term treatment outcomes (Crossley, Stefanik, et al., 2016; Glaviano \& Saliba, 2016; Powers, Bolgla, Callaghan, Collins, \& Sheehan, 2012; Witvrouw et al., 2014).

This masterclass aims to introduce the clinician to currently proposed theories linked to the aetiology of PFP, and the multiple potential factors related to PFP symptom development and persistence. This information will then be used as foundation knowledge to inform clinical assessment and provide insight into potentially effective treatments, along with discussion of areas where greater understanding is still required. Importantly, the masterclass will provide practical tools and resources that can be directly implemented into clinical practice.

\subsection{Why does it hurt? Proposed theories linked to the aetiology of patellofemoral pain}

\subsubsection{Biomechanical model}

Traditional paradigms of pain presentation have been derived from a primary nociceptive pathway directly associated with overload of the PFJ. It has been proposed that alterations in lower limb biomechanics result in maltracking of the patella within the trochlea groove (Fig. 1) (Powers, 2010). Multiple potential mechanisms are thought to result in PFJ maltracking, including movement of the patella relative to the femur, or the femur underneath the patella driven by proximal or distal biomechanical variables (Lee, Morris, \& Csintalan, 2003; Witvrouw et al., 2014). Theoretically, this maltracking subsequently increases PFJ stress, initiating nociceptive firing from the densely innervated subchondral bone (Powers, 2003). Evidence related to the validity of this proposed biomechanical model is outlined in the "common biomechanical deficits reported in PFP' section below. Whilst it remains plausible that this represents the primary nociceptive pathway for some individuals, the complexity of the central nervous system within which this peripheral nociception is processed, requires the clinician to be considerate of the individuals psychosocial characteristics in addition to biological theories and concepts (Maclachlan, Collins, Matthews, Hodges, \& Vicenzino, 2017).

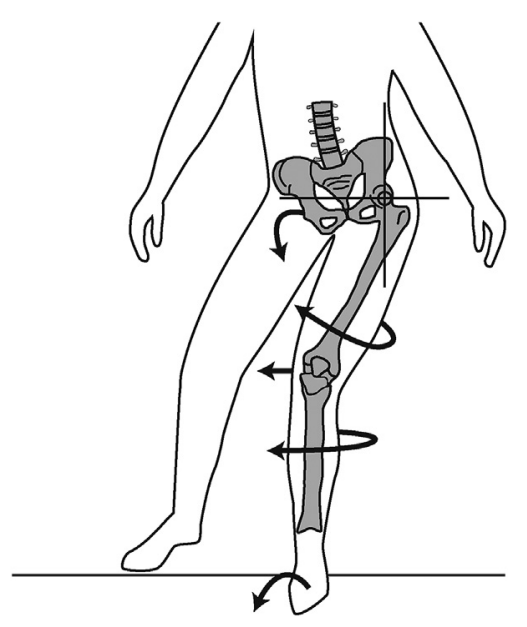

Fig. 1. Demonstrating altered biomechanics leading to the maltracking of the patella within the trochlea groove - from proximal to distal the arrows indicate, contralateral pelvic drop, internal femoral rotation, knee valgus, internal tibial rotation and foot pronation (Reprinted with permission (Barton \& Rathleff, 2016)).

\subsubsection{Tissue homeostasis}

In 1999, Scott Dye and colleagues proposed a tissue homeostasis model for the development of PFP, describing how relative supraphysiological over- or under-load on innervated musculoskeletal tissues in the region of the PFJ, may result in symptoms (Dye, Stäubli, Biedert, \& Vaupel, 1999) (Fig. 2). It has subsequently been described how a resultant single loading event of sufficient magnitude or a number of repeated loading events of lower magnitude may result in the loss of tissue homeostasis, at least temporarily, and subsequent increase in nociceptive firing (Dye, 2005).

\subsubsection{Proposed structural source of symptoms}

Prior to and following the suggestion of a homeostasis model, a number of potential tissue derived characteristics may be present in those with PFP symptoms (Fulkerson, 1983; Ho et al., 2014; Sanchis-Alfonso et al., 1998; Schoots, Tak, Veenstra, Krebbers, \& Bax, 2013; van der Heijden et al., 2016). These included alterations in the neovascularity and thickness of the lateral retinaculum, increased water content of the subchondral bone and articular cartilage stress (Farrokhi, Keyak, \& Powers, 2011; Ho et al., 2014; Schoots et al., 2013). The absence of association between changes in cartilage composition and PFP symptoms continues to challenge the assumption that patient's pain can be explained by structural changes in isolation (van der Heijden et al., 2016).

\subsubsection{Non-mechanical contributors to pain}

Despite nociceptive activity representing the dominant mechanism of acute pain, the large number of individuals with recurrent or persistent PFP symptoms means that exploration of possible non-mechanical contributors to symptom persistence is warranted (Arendt-Nielsen, Skou, Nielsen, \& Petersen, 2015). The biomedical model in isolation possesses inherent limitations within the complex paradigm of human pain perception (Gifford \& Butler, 1997) and a treating clinician may need to prioritise assessment of the unique filters through which an individual's nociceptive signals pass.

In some, the non-mechanical amplification of nociceptive signalling that can occur within both the peripheral and central nervous systems (pain sensitisation), may be the predominant driver of pain perception and persistence. In both adolescents (Rathleff, Roos, Olesen, Rasmussen, \& Arendt-Nielsen, 2013) and female

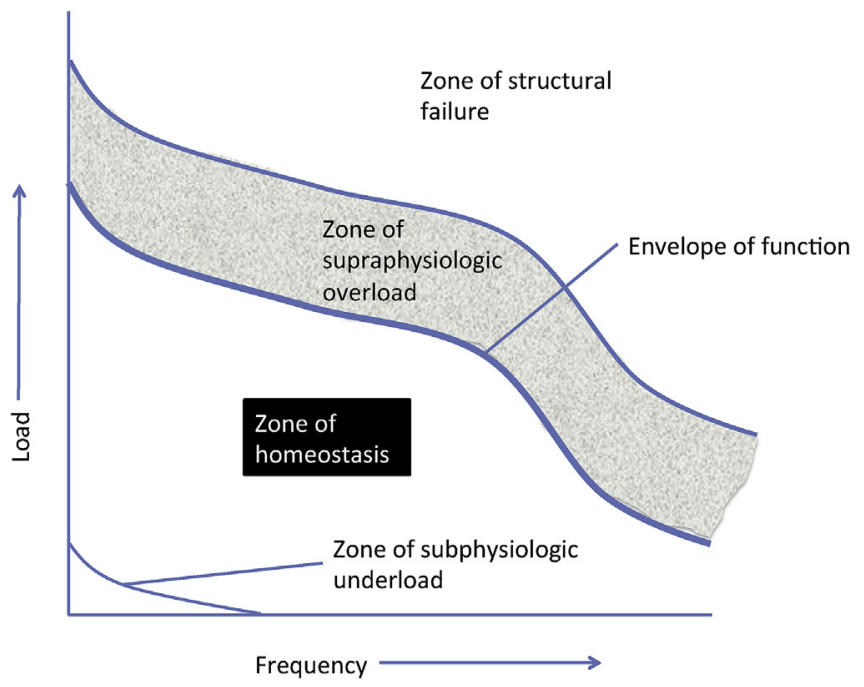

Fig. 2. Diagrammatic representation of the zone of tissue homeostasis reproduced (with permission) from Dye 1999 (Dye et al., 1999). 
adults (Pazzinatto et al., 2016; Rathleff, Petersen, Arendt-Nielsen, Thorborg, \& Graven-Nielsen, 2015) with persistent PFP symptoms, local and widespread hyperalgesia has been reported, thought to represent altered pain processing. The activities that load the PFJ (e.g. stair negotiation, squatting, walking, running) may generate repetitive nociceptive stimuli, leading to the development and maintenance of pain sensitisation. A recent study provides support for this assumption, as greater running volume was associated with localized and remote pressure hyperalgesia and poorer self-reported knee function in female runners with PFP (Pazzinatto et al., 2017).

Elevated levels of anxiety, depression, catastrophising and fear of movement have also been reported in individuals with PFP, which have the capacity to negatively influence physical function and activity related behaviours (Maclachlan et al., 2017). These observations, in combination with reductions in pain and disability being associated with improvements in psychosocial health (Doménech, Sanchis-Alfonso, \& Espejo, 2014), highlight the importance of recognising alterations in a patient's pain processing during clinical examination and integrating these findings into their eventual management plan (Maclachlan et al., 2017).

\subsection{Common biomechanical deficits reported in PFP}

Proximal, distal and local to the PFJ, biomechanical deficits are evident in people with PFP. In some instances these deficits may exist prior to the development of symptoms, potentially representative of the primary driver of symptoms through resultant altered loading and loss of tissue homeostasis about the PFJ (Dye, 2005). To optimise treatment, individual patient deficits need to be identified and an appropriately tailored intervention programme developed and delivered.

The most frequently investigated muscle local to the PFJ is the quadriceps, with prospective level one evidence indicating PFP development is more common in individuals with reduced knee extension strength (Lankhorst, Bierma-Zeinstra, \& van Middelkoop, 2012), level two evidence indicating VMO is delayed in those who develop PFP (Van Tiggelen, Cowan, Coorevits, Duvigneaud, \& Witvrouw, 2009) and level one retrospective evidence reporting reduced quadriceps cross sectional area in those with symptoms (Giles, Webster, McClelland, \& Cook, 2013). The prospective data is, however, limited to military populations (Boling et al., 2009; Duvigneaud, Bernard, Stevens, Witvrouw, \& Van Tiggelen, 2008; Van Tiggelen et al., 2009) and it is currently unclear if quadriceps weakness or VMO activation delays increase the risk of PFP development in non-military populations. Consistent crosssectional findings indicate decreased knee extension strength exists in various populations with PFP symptoms (Lankhorst, BiermaZeinstra, \& van Middelkoop, 2013), including recreational runners and physically active individuals. It is important to note that the same quadriceps muscle strength deficits reported in adults with PFP have not been reported to exist in adolescents with PFP, potentially indicating exercise therapy targeting strength in this population may be less beneficial or relevant (Rathleff, Baird, et al., 2013).

Kinematically, individuals with PFP are reported to ascend stairs with reduced peak knee flexion when compared to healthy controls (Crossley, Cowan, Bennell, \& McConnell, 2004; de Oliveira Silva, Briani, Pazzinatto, Ferrari, Aragão, \& de Azevedo, 2015), which may be reflective of kinesiophobia, or an attempt, conscious or unconscious, to decrease symptoms through a reduction of PFJ and quadriceps loading requirements (Salsich, Brechter, \& Powers, 2001).

The relationship between hip strength and symptom development is unclear, with previous prospective studies reporting either increased hip abduction strength (Herbst et al., 2015; Ramskov, Barton, Nielsen, \& Rasmussen, 2015) or no association between hip abduction strength and increased risk of future PFP development (Herbst et al., 2015; Ramskov et al., 2015; Rathleff, Rathleff, Crossley, \& Barton, 2014). Cross-sectional studies have reported more consistent evidence for decreased hip abduction, extension and external rotation strength (Rathleff et al., 2014), along with a delayed and shorter duration of gluteal muscle activity during functional tasks (Barton, Balachandar, Lack, \& Morrissey., 2014), in people with PFP. In addition, emerging evidence indicates rate of force development in females with PFP may also be slower when compared to asymptomatic females (Nunes, Barton, \& Serrão, 2017), suggesting that muscle function variables in addition to strength should be of interest to those delivering PFP rehabilitation. Consistent with quadriceps findings, hip muscle weakness is reported to exist in older (15-19y/o) but not younger (12-16y/o) adolescents with PFP (Rathleff, Baird, et al., 2013). This indicates proximal muscle deficits may develop as a result of PFP symptoms rather than be a causative factor. Nevertheless, considering potential effects of the hip on knee mechanics, these deficits represent a key treatment target.

Proximal kinematic factors have been reported to be associated with a greater risk of developing PFP. Specifically, increased peak hip internal rotation during a double leg drop landing was reported in a predominantly male military cohort during jump landing who developed PFP compared to those who did not (Boling et al., 2009). Additionally, increased peak hip adduction during running was reported in a group of females who developed PFP compared to those who did not (Noehren, Hamill, \& Davis, 2013). This profile of greater hip adduction and internal rotation also appears to exist consistently during running once symptoms have developed (Neal, Barton, Gallie, O'Halloran, \& Morrissey, 2016). Interestingly, the same link is not seen during walking, where less peak internal rotation has been reported in people with PFP (Barton, Bonanno, Levinger, \& Menz, 2010; Powers, 2003). It is predominantly the female sex where associations between hip biomechanics and PFP are seen, whereas an increase in peak knee adduction has been reported in male runners with PFP compared to female runners with PFP (Willy, Manal, Witvrouw, \& Davis, 2012). Overall, the lower limb biomechanical differences between the sexes during high impact tasks have not been fully investigated and further work is required in this field.

Distal to the PFJ, coupling between rearfoot eversion and tibial rotation has been proposed to influence PFJ mechanics (Fig. 3) (Tiberio, 1987), possibly driving symptom development or persistence. Specifically, a theoretical paradigm of prolonged or increased rearfoot eversion, increasing tibial internal rotation and resulting in a compensatory increase in femoral internal rotation to achieve knee extension has been proposed (Tiberio, 1987). The consequence of this coupled movement is proposed to be elevated loading between the lateral femoral condyle and lateral facet of the patella (Lee et al., 2003; Tiberio, 1987). Subsequent investigation of this proposed coupled movement in individuals with PFP has been conflicting (Barton, Levinger, Crossley, Webster, \& Menz, 2012; Powers, Chen, Reischl, \& Perry, 2002). Individuals with PFP symptoms are reported to demonstrate a more pronated foot posture both statically (Lankhorst et al., 2013) and quasi statically (normalised navicular drop) (Barton et al., 2010) when compared to those without pain. However, the potential impact of these findings on dynamic function is unclear (Barton, Levinger, Crossley, Webster, \& Menz, 2011; McPoil \& Cornwall, 1996). Prospectively, increased navicular drop has been reported as a risk factor for future symptom development in a military population (Boling et al., 2009; Neal et al., 2014), but the small difference between those who did and did not develop pain $(<1 \mathrm{~mm})$ means the finding may be of 


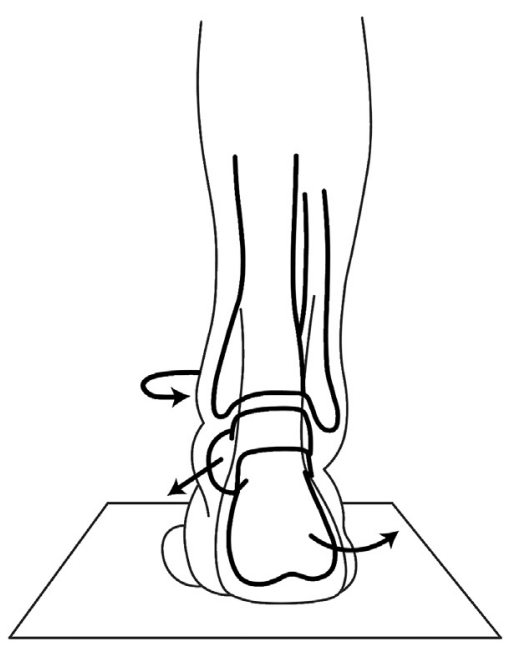

Fig. 3. A diagrammatic presentation of the coupling between rearfoot motion and shank motion (Right foot) adapted from (Tiberio, 1987).

questionable clinical relevance. Overall, the relevance of static alignment remains unclear warranting only limited attention during the assessment of the patient with PFP.

Dynamically, there does not appear to be any differences in peak rear- or forefoot motion between people with and without PFP during running (Noehren, Pohl, Sanchez, Cunningham, \& Lattermann, 2012; Powers et al., 2002) or walking (Barton et al., 2011). However, during stair ascent and running, higher rearfoot eversion and a greater percentage of the available pronation range utilised in those with PFP respectively, has been reported (de Oliveira Silva, Barton, Pazzinatto, Briani, \& de Azevedo, 2016; de Oliveira Silva, Briani, Pazzinatto, Ferrari, Aragão, de Albuquerque et al., 2015; Rodrigues, TenBroek, \& Hamill, 2013). Plantar pressure evaluation in previous literature seems to provide a stronger link between foot function and PFP. Specifically, increased laterally directed pressure distribution at initial foot contact, shorter time to maximal pressure on the 4th metatarsal during running (Thijs, De Clercq, Roosen, \& Witvrouw, 2008) and slower maximal velocity of the change in lateromedial direction of the centre of pressure during forefoot contact during walking, have been reported to be associated with high risk of PFP development (Thijs et al., 2007). The mechanistic link between these biomechanical variables and symptom development has not been established, but may be indicative of decreased foot pronation during the loading phase of gait, resulting in reduced load absorption and thus an increased transfer of forces proximally to the patellofemoral joint (Dowling et al., 2014; Neal et al., 2015).

The presentation of biomechanical deficits in people with PFP is both common and varied (Ferrari et al., 2018; Fox, Ferber, Saunders, Osis, \& Bonacci, 2017). Following the assessment of proximal, local and distal kinematics during stair ascent, $52 \%$ of females presented at least two kinematic alterations and three kinematic alterations were found in $48 \%$ of the females with PFP (Fig. 4) (Ferrari et al., 2018). A higher number of kinematic alterations were strongly associated $(r=0.78)$ with higher levels of pain and lower functional status (Ferrari et al., 2018) and those with chronic PFP have been reported to differ throughout the kinetic chain compared with an acute PFP population and controls (Fox et al., 2017). Therefore, clinicians should carefully assess the movement patterns throughout the kinetic chain during different tasks, as identified biomechanical deficits may indicate a more severe condition and can help guide an individual specific treatment plan.

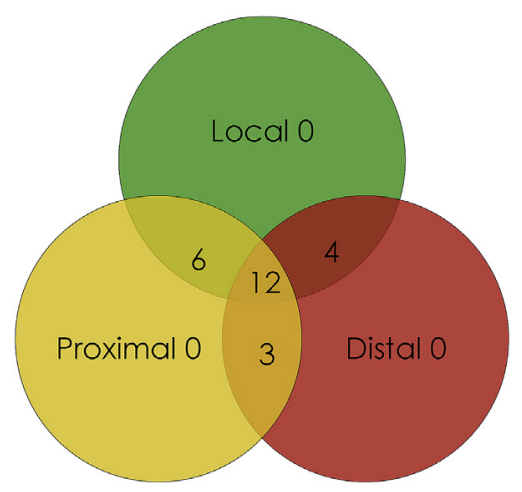

Fig. 4. Demonstrating the distribution of kinematic deficits, local, distal and proximal to the PFJ in individuals with PFP, reprinted (with permission) from Ferrari et al., 2018 (Ferrari et al., 2018).

\section{Assessment}

We recently developed a 'Best Practice Guide' for managing PFP by combining systematic review findings with qualitative interviews of international experts in order to guide clinical decisionmaking and inform evidence based treatment delivery (Barton et al., 2015). This synthesis of evidence highlights that in order to effectively manage the multifactorial nature of PFP, consideration of multiple different intervention approaches is required (Table 1) (Barton et al., 2015). To effectively direct and deliver a tailored treatment plan a multi-dimensional assessment, to identify the drivers of the individual's symptoms, must be adopted (Fig. 5). Careful questioning should be adopted throughout the subjective examination, with the appropriate use of reflective questioning to increase the patients understanding of the problem from the outset (Lee \& Barnett, 1994). Examples include, 'How do you think that significant increase, compared with your normal exercise volumes, affected your knee pain?' and 'Considering similar changes in knee cap cartilage are observed in people with and without pain, how much do you think your scan results explain the symptoms you have?'.

\subsection{Structure and pathology}

Assessment of the individuals underlying structure and degree of joint pathology may be important to objectify in some presentations of PFP. However, consistent with emerging evidence in other common musculoskeletal conditions such as low back pain (Baker, 2014; Jensen et al., 1994), the correlation between structure and symptoms has been shown to be tenuous in those with PFP (Stefanik et al., 2014). Imaging findings should have limited impact on treatment decisions in most cases, and clinicians who are working with patients seeking interventions aiming to address structure or structural pathology should ensure adequate time is spent discussing the available evidence (Barton \& Crossley, 2016) as they either lack evidence to support their use (e.g. platelet-rich plasma injections) or are unsupported in RCTs (e.g. arthroscopy surgery) (Kettunen et al., 2007, 2012). Practitioners treating PFP should be encouraged to carefully consider the purpose of requesting imaging and should ensure the patient is well educated on the relevance of structural changes identified following imaging investigations.

\subsection{Biomechanics}

Pragmatic clinical measures such as a single leg squat have been 
Table 1

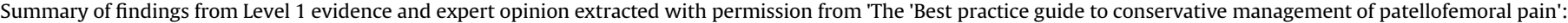
incorporating level 1 evidence with expert clinical reasoning (Barton et al., 2015).

\begin{tabular}{|c|c|c|}
\hline EDUCATION & ACTIVE REHABILITATION & PASSIVE INTERVENTIONS \\
\hline $\begin{array}{l}\text { 1. Ensure patients understand potential } \\
\text { contributing factors to their condition } \\
\text { and treatment options } \\
\text { 2. Advise about appropriate activity } \\
\text { modification } \\
\text { 3. Manage patients expectations regarding } \\
\text { rehabilitation } \\
\text { 4. Encourage and emphasise the importance } \\
\text { of participation in active rehabilitation }\end{array}$ & $\begin{array}{l}\text { Principles } 1 \text {. Give preference to CKC exercises to replicate } \\
\text { function } \\
\text { 2. Consider OKC exercises in early stages of rehabilitation to } \\
\text { target specific strength deficits and movements } \\
\text { 3. Provide adequate supervision in the early stages to ensure } \\
\text { correct exercise techniques, but progress to independence } \\
\text { as soon as possible } \\
\text { 4. When independent, limit the number of exercises to } 3 \text { or } 4 \\
\text { to aid compliance } \\
\text { 5. Use biofeedback such as mirrors and videos to improve } \\
\text { exercise quality } \\
\text { Specifics } \\
\text { 1. Incorporate quadriceps and gluteal strengthening } \\
\text { 2. Target distal and core muscles where deficits exist } \\
\text { 3. Consider stretching, particularly of the calf and hamstrings, } \\
\text { based on assessment findings } \\
\text { 4. Incorporate movement pattern retraining, particularly of } \\
\text { the hip }\end{array}$ & $\begin{array}{l}\text { Pain reduction 1. Provide tailored patellar taping to } \\
\text { reduce pain in the immediate term } \\
\text { 2. Consider PFJ braces where taping is inappropriate (e.g. } \\
\text { skin irritation) } \\
\text { 3. Consider foot orthoses } \\
\text { Optimising biomechanics1. Consider foot orthoses based on } \\
\text { assessment findings (i.e. } \\
\text { presence of excessive dynamic } \\
\text { pronation) } \\
\text { 2. Consider massage and acupuncture/dry needling to } \\
\text { improve the flexibility of tight muscle and fasciae } \\
\text { structures, particularly laterally } \\
\text { 3. Consider PFJ mobilisation but only in the presence of } \\
\text { hypo-mobility } \\
\text { 4. Consider mobilisation of the ankle and first ray in the } \\
\text { presence of sagittal plane joint restriction }\end{array}$ \\
\hline
\end{tabular}

Comments in bold are supported by Level 1 evidence

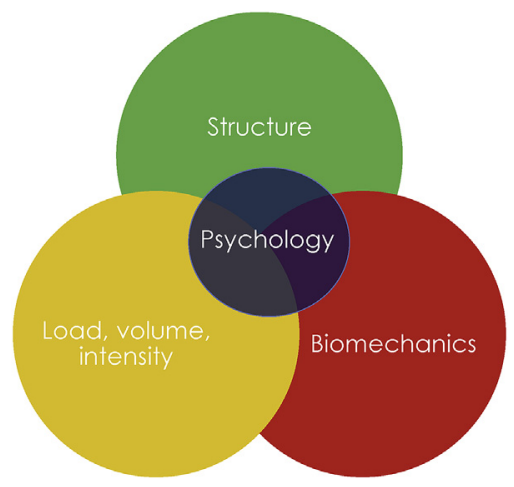

Fig. 5. Diagrammatic representation of the multiple domains that require consideration during the assessment of an individual with PFP.

proposed to detect movement deficits (Whatman, Hing, \& Hume, 2011, 2012) and altered neuromuscular function (Crossley, Zhang, Schache, Bryant, \& Cowan, 2011). However, the clinical impact of targeting changes in mechanics observed during a single leg squat needs to be scrutinised, as improvement in the tasks performance is unlikely to lead to movement pattern changes during other more dynamic tasks such as running (Willy \& Davis, 2011). To maximise the relevance of findings to the individual patient's presentation, assessment of functional movement patterns should be evaluated during specific tasks the patient reports as painful (e.g. running, jumping/hopping, squatting and sit to stand). Movement can be observed in comparison to the asymptomatic or less symptomatic limb, and integrated within the wider context of the individual's presentation. Adoption of this assessment approach allows for the appropriate weighting of interventions that aim to address these deficits. Incorporating movement modification strategies using hands on approaches, taping or appropriate cueing, and gauging the immediate effect on reported symptoms offers useful insight into the strength of association between the identified movement deficit and the patients pain.

\subsection{Volume, frequency and intensity}

Quantification of the volume, frequency and intensity of load that an individual is imposing on their PFJ should form an integral part of the subjective assessment. Questioning should be directly related to the patient's training, activity and playing habits to gain insight into the role of these variables on symptom development and/or persistence. Additionally, questions related to extrinsic factors affecting load may also offer useful insight, including the influence of coaches, parents, teachers and training environment to allow for adequate rest and recovery. These factors may be particularly important in some adolescent patients, given the high prevalence of PFP in this population (6.95\% of 2200 adolescents (Rathleff, Rathleff, Olesen, Rasmussen, \& Roos, 2016)) and commonly reported absence of strength deficits (Rathleff, Baird, et al., 2013), as they can often be fully immersed in sporting activities and influenced by those who care for them. Importantly, education relating to load management has been shown to have a positive effect on symptoms (Esculier et al., 2018; Rathleff, Roos, Olesen, \& Rasmussen, 2015) and optimal load management and progression shown to reduce the risk of other injuries in varying sporting populations (Gabbett et al., 2016; Murray, Gabbett, \& Townshend, 2016; Windt, Gabbett, Ferris, \& Khan, 2017). Therefore, accurate quantification and consideration of its relevance to the patient's symptom development during their assessment and development of a treatment plan, is essential.

\subsection{Psychology}

An individuals psychology has been reported to represent an important factor in the persistence of symptoms in a sub-group of individuals with PFP (Maclachlan et al., 2017; Maclachlan, Matthews, Hodges, Collins, \& Vicenzino, 2018). For some, behaviours associated with change in psychology may represent a driver for symptom development (e.g. increased training volumes to manage stress or low mood), but this hypothesis is yet to be tested within a prospective study design. Incorporating measures of psychological health into the initial assessment in those with PFP (e.g. using the Orebro Musculoskeletal Pain Questionnaire, Hospital 
Anxiety and Depression Scale, Tampa Scale for Kinesiophobia and/ or Fear Avoidance Beliefs Questionnaire) can offer useful insight into levels of anxiety, fear or depression associated with their pain presentation (French, France, Vigneau, French, \& Evans, 2007; Johnston, Pollard, \& Hennessey, 2000; Linton \& Boersma, 2003; Swinkels-Meewisse, Swinkels, Verbeek, Vlaeyen, \& Oostendorp, 2003). Interventions specifically directed at these markers of psychological health in those with PFP have not been explored (Maclachlan et al., 2017). However, within other persistent musculoskeletal (MSK) complaints such as low back pain, the positive role of cognitive behavioural interventions have been reported (Cherkin et al., 2017; O'Sullivan, 2005), indicating similar approaches may be worthy of consideration in PFP. Appropriate onward referral to a suitably qualified health professional (e.g. psychologist) should be considered if indicated based on the patient's psychological assessment. Further research in this area in people with PFP is required before we can provide clear recommendations of the most appropriate interventional approach.

\section{Treatment}

The development and implementation of an individually tailored treatment plan, that incorporates interventions of proven efficacy (Fig. 6), follows the detailed assessment of the individual. Whilst interventions that aim to address specific deficits are advocated, the current recommended physical interventions for the management of PFP include approaches that combine more than one treatment approach (Crossley, Stefanik, et al., 2016). A greater understanding of the potential mechanisms of treatment effects is required to improve the accuracy with which tailored treatment approaches are delivered (Crossley, Stefanik, et al., 2016). Clinicians are encouraged to incorporate one or all of the treatment approaches presented below if indicated following clinical assessment.

\subsection{Exercise therapy}

Based on current evidence and clinical practice, exercise therapy forms the cornerstone of management for PFP (Crossley, Stefanik, et al., 2016; Lack, Barton, Sohan, Crossley, \& Morrissey, 2015; van der Heijden et al., 2015) and traditionally, exercise has focussed on the knee musculature. However, findings from a recent systematic review indicate that proximally targeted exercise, when added to knee targeted exercise, may improve symptoms and

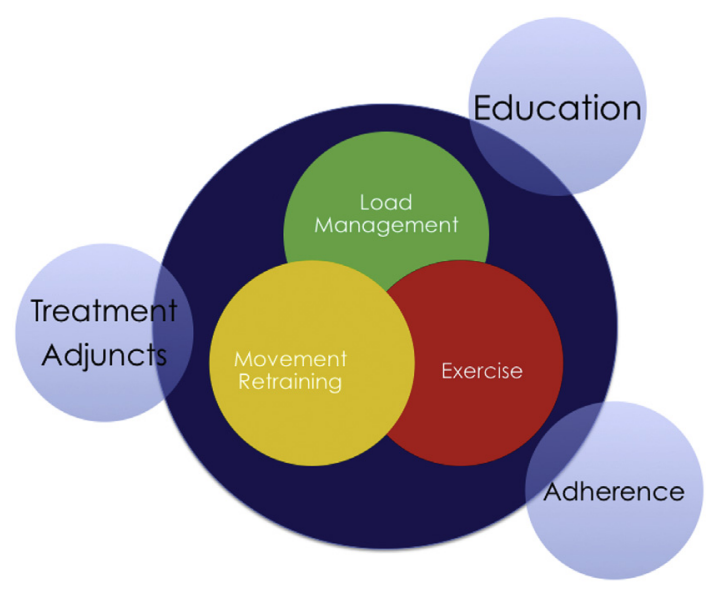

Fig. 6. Demonstrating the integrated approach of interventions with proven efficacy (figure created with the assistance of Dr Michael Rathleff). function in the short ( $<3$ months), medium (3-12 months) and longer term ( $>12$ months) (Lack et al., 2015). Additionally, in the early stages of rehabilitation (first 6 months), proximally targeted exercise may improve pain and function to a greater extent than knee targeted exercise. These more recent advances in our understanding of exercise therapy for PFP highlight that the early $(<6$ months) focus of exercise prescription should be proximal rehabilitation to improve hip strength and mechanics, particularly in patients where knee targeted exercises may exacerbate symptoms.

Whilst the mechanism for exercise intervention has not been definitively established, several authors have investigated the potential mechanisms of effect following exercise therapy. Locally, changes in timing of the vasti muscles (Cowan, Bennell, Crossley, Hodges, \& McConnell, 2002; Witvrouw et al., 2003), and increased isometric quadriceps strength (Hazneci, Yildiz, Sekir, Aydin, \& Kalyon, 2005; Witvrouw et al., 2004) have been reported. Proximally, hip strength gains (Khayambashi, Mohammadkhani, Ghaznavi, Lyle, \& Powers, 2012) and reduced knee valgus variability (Ferber, Kendall, \& Farr, 2011) during running has been reported in rehabilitation groups compared to no intervention control groups.

Based on limited evidence, our review of the proximal rehabilitation literature identified no significant improvements in strength at the hip following proximal or proximal combined with knee targeted exercise when compared to a knee targeted exercise alone (Lack et al., 2015). This is despite significantly greater symptom reduction reported for programs targeting the proximal musculature (Lack et al., 2015). The reason of no difference between these groups could be explained by the progression of quadriceps rehabilitation to closed kinetic chain (CKC) exercises. During CKC exercises, the proximal muscles will also be receiving a loading stimulus that may be sufficient to match the beneficial changes of an isolated proximal rehabilitation programme.

Although the beneficial effect of exercise therapy is strong, it is not possible to replicate previously published exercise protocols for PFP (Holden, Rathleff, Jensen, \& Barton, 2017). Additionally, the majority of previous studies appear to focus on neuromuscular or strength-endurance prescription, despite stating a focus on strength in their titles (Lack et al., 2015). Considering possible deficits in strength (Rathleff et al., 2014) and muscle power (Nunes et al., 2017), we encourage clinicians to assess each patient for specific muscle function deficits, and prescribe a specific progressive resistance training program accordingly. Where necessary, design of an appropriate programme should aim to use accepted exercise prescription principles (Fig. 7) (American College of Sports, 2009).

In addition, further considerations should be made to ensure the exercise prescription delivers an appropriate time under tension, load magnitude and numbers of sets and repetitions, to optimise the specificity of the prescription to achieve the desired physiological response (Toigo \& Boutellier, 2006) (see http:// patellofemoral.trekeducation.org/).

Short-term rehabilitation programs rarely provide additional benefit when evaluated in the longer term (e.g. 12 months after enrolment), and in some cases initial benefits compared to control interventions diminish over time (Lack et al., 2015; van der Heijden et al., 2015). Considering potential long standing pain and kinesiophopia (Domenech, Sanchis-Alfonso, López, \& Espejo, 2013), and associated strength deficits and muscle atrophy (Giles et al., 2013; Lankhorst et al., 2013) in PFP, this is not surprising. Put simply, fully addressing significant muscle function deficits will take time - far longer than the 3-8 weeks of rehabilitation intervention that has commonly been described within the current evidence base.

Large neural adaptations occur in the early stages of any resistance training (American College of Sports, 2009; Sale, 1988), and 


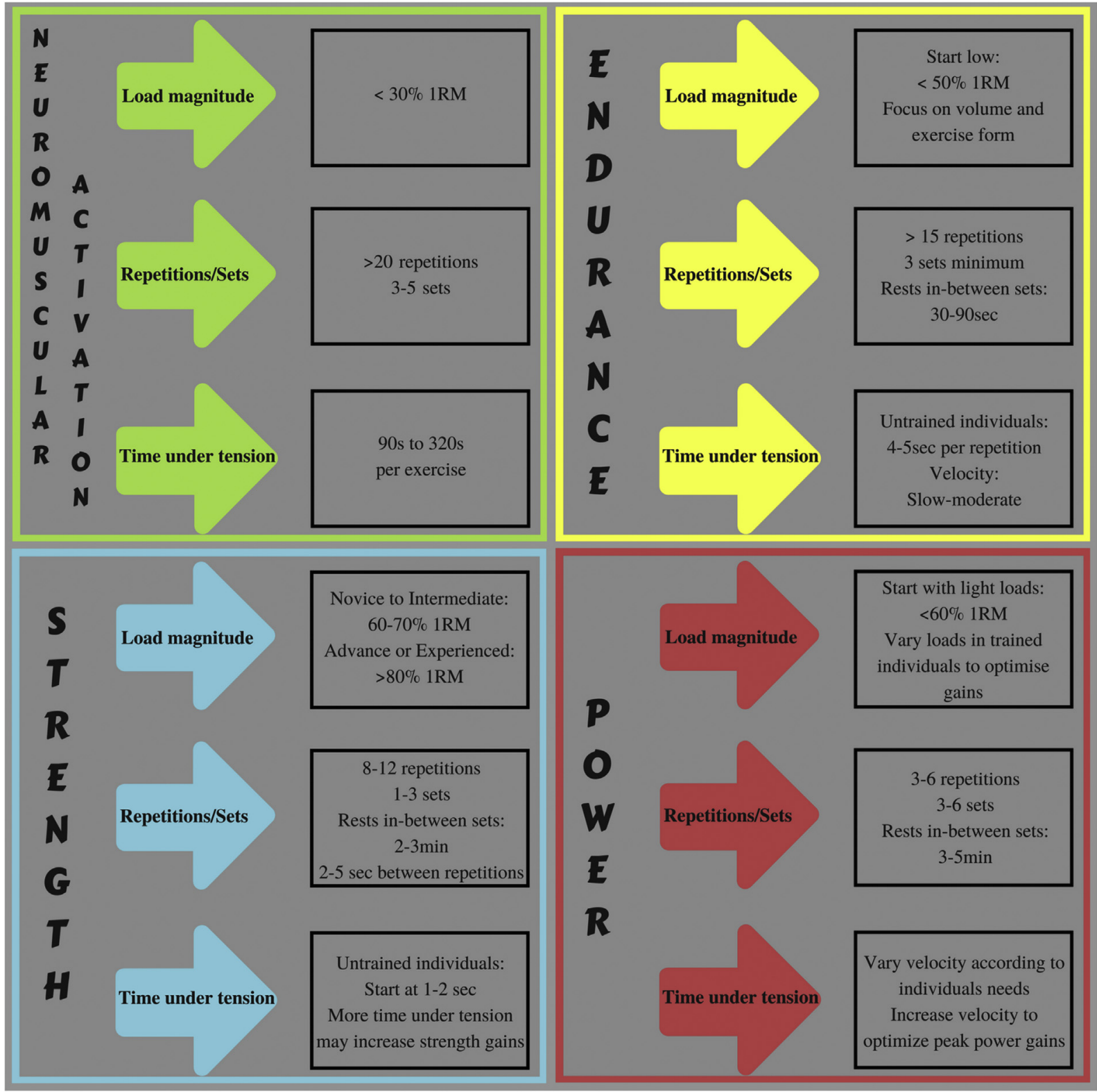

Fig. 7. Exercise prescription principles.

hence these are likely to explain a lot of improvement from previously evaluated exercise rehabilitation programs in PFP management (Lack et al., 2015; van der Heijden et al., 2015). However, true muscle hypertrophy, which may be required to address muscle atrophy in individuals with PFP, is much slower, taking around 6 weeks before signs of hypertrophy are evident. Improvements are unlikely to plateau for at least 6 months in healthy adults (American College of Sports, 2009), and in the presence of muscle atrophy as a result of PFP, we believe this time period may be much longer. Whilst in all therapy environments treatment delivery over longer time periods is not feasible, follow up for at least 12 months following commencement of rehabilitation is desirable.

Current research comparing differing exercise dosage in PFP rehabilitation is limited, and requires attention. However, in a previous randomised trial comparing exercise dose and outcomes in PFP, higher dose $(3 \times / \mathrm{wk}, 3 \times 30$ reps, 9 exercises, $60 \mathrm{~min} \mathrm{~s})$ was reported to be more effective than lower dose $(3 \times / \mathrm{wk}, 2 \times 10$ reps, 5 exercises, $20 \mathrm{mins}$ ) exercise prescription (Østerås, Østerås,
Torstensen, \& Vasseljen, 2013). Additionally, the only study reporting improvements in pain at 1 year follow up used exercise intensities of $>70 \%$ of 1 repetition maximum (1RM) (Fukuda et al., 2012). This exercise prescription is consistent with recommendations that novice to intermediate individuals train with loads corresponding to $60-70 \%$ of $1 \mathrm{RM}$ for $8-12$ repetitions to maximise strength increases (American College of Sports, 2009).

In most cases, home exercise including the use of resistance bands and body weight exercise is appropriate in the early stages of rehabilitation and the majority of clinical trials supporting the efficacy of exercise rehabilitation in PFP have used this approach (Lack et al., 2015; van der Heijden et al., 2015). When commencing any resistance training program, low to moderate intensity exercise prescription is recommended to facilitate muscle function (strength, power and endurance) improvements (American College of Sports, 2009). However, progressing from home based to gym based rehabilitation may be an important step in optimising the management of PFP, particularly in patients who wish to return to 
activities where knee and other lower limb joint forces increase significantly (e.g. stair negotiation and running). Gym based resistance training, a minimum of 2 times per week, will allow the prescription of progressive overload, and hence optimal muscle function improvements (American College of Sports, 2009).

Although exercise prescription should be tailored at the beginning of rehabilitation to prioritise addressing key deficits (e.g. muscle activation or soft tissue flexibility), evolution of the program must be guided to ensure all potential deficits are addressed over time. There are no recipes, and progression requires careful on-going assessment by the treating clinician. Consideration should be given to specific deficits, including type of muscle activation (concentric, eccentric, isometric), movement velocity and power, endurance, range of motion, and muscle group (quadriceps, gluteal, etc.). Additionally, the patient's functional goals must also be considered. To achieve these treatment goals, patients will need to continue with an exercise programme into the longer term (>6months). Clinicians may need to develop a gym-based resistance programme that the patient has the skills and knowledge to progress independently beyond the course of supervised physiotherapy treatment.

\subsection{Movement/Run retraining}

There is evidence to suggest that an exercise intervention targeting muscle function (e.g. strength) may not change movement patterns (kinematics) during a specific high load task like running (Sheerin, Hume, \& Whatman, 2012; Willy \& Davis, 2011; Wouters et al., 2012). For a sub-group of individuals with movement pattern deficits that have contributed to their symptom development (Noehren et al., 2013), this may explain the poor long-term outcomes seen post exercise-only programs (Collins et al., 2013; Witvrouw et al., 2004).

Movement pattern retraining for individuals with PFP is receiving growing attention in research and clinical practice, and has been recommended by international experts (Barton et al., 2015). In female runners with excessive peak hip adduction $\left(>20^{\circ}\right)$ and PFP, emerging evidence indicates visual and verbal cues are effective at reducing hip adduction angles and patient reported symptoms (Noehren, Scholz, \& Davis, 2011; Willy, Scholz, \& Davis, 2012). Strategies to reduce hip adduction may be particularly important considering that excessive peak hip adduction during running is reported to be a risk factor for PFP development (Noehren et al., 2013), and exercise in individuals with PFP does not seem to address this deficit (Earl \& Hoch, 2011; Ferber et al., 2011). Similar cueing to reduce hip adduction and internal rotation during other activities that increase loading on the PFJ such as squatting and stair negotiation may also be an important part of rehabilitation in patients with PFP. The need for movement pattern retraining should be assessed on an individual basis, and can be aided by video and mirror feedback in the clinic (Barton et al., 2015).

More recent research has evaluated other movement pattern retraining strategies for runners with PFP, reporting mixed results. Roper et al. (Roper et al., 2016) reported a significant short-term reduction in pain after external cueing to transition to a forefoot strike pattern, compared to load management control. In addition, Bonacci et al. (Bonacci, Hall, Saunders, \& Vicenzino, 2018) reported a significant short-term reduction in pain after external cueing to increase step rate to match a metronome beat, combined with the use of a minimalist shoe, in comparison to prefabricated foot orthoses. In contrast, Esculier et al. (Esculier et al., 2018) evaluated the additional benefit of increasing step rate with the option of transitioning to a non-rearfoot strike pattern if the treating clinician deemed necessary, but reported no additional benefit of this running retraining protocol compared to load management education.
This variance in outcome could be explained by the lower feedback dosage delivered by Esculier at al. (five ten minute sessions over 8 weeks) (Esculier et al., 2018), compared to both Roper et al. ( 8 sessions over 2 weeks) (Roper et al., 2016) and Bonacci et al. (10 sessions over 6 weeks) (Bonacci et al., 2018). It should also be noted that feedback targeting a specific movement deficit (high peak hip adduction and a rearfoot strike pattern respectively) was adopted in three comparable studies (Bonacci et al., 2018; Roper et al., 2016; Willy, Scholz, et al., 2012), whereas Esculier et al. (Esculier et al., 2018) utilised a step rate cue that may not have been required by all participants within their cohort. Finally, there was no faded-feedback protocol employed within the retraining design of Esculier et al. (Esculier et al., 2018), found to be effective by multiple previous studies (Noehren et al., 2011; Roper et al., 2016; Willy, Scholz, et al., 2012). Whilst the emerging evidence from differing study designs (no RCT's) presents conflicting findings, the most recent systematic review of the literature indicates running retraining strategies are beneficial for short-term improvements in running specific PFP (Neal et al., 2016). Delivering movement pattern retraining targeting a specific deficit and using a fadedfeedback protocol, where feedback is optimised (acquisition phase) and then gradually reduced (transfer phase), is recommended to optimise the potential for skill acquisition (Noehren et al., 2011; Willy, Scholz, et al., 2012) (See http://patellofemoral. trekeducation.org/).

\subsection{Passive adjuncts}

Two passive interventions possess evidence of benefit in the short term (i.e. 4-6 weeks), and warrant consideration in the management of PFP.

\subsubsection{Taping}

Taping interventions for PFP published in the literature vary in terms of application and follow up time. Level one evidence identified moderate evidence that tailored (large effect) and untailored (small effect) patellar taping immediately reduces pain, and tailored patellar taping promotes an earlier onset of the vastus medialis oblique (VMO) relative to vastus lateralis (VL) (Barton, Balachandar et al., 2014). The important distinction related to tailoring is that lateral patellar tilt, glide and rotation are targeted until a minimum $50 \%$ pain reduction during a functional task (e.g. step down) is achieved (McConnell, 1996). Untailored taping tends to involve just one strip of tape that targets lateral glide of the patella. Further guidance on the two methods is provided at http:// patellofemoral.trekeducation.org/.

Beyond the immediate term, limited evidence also indicates tailored patellar taping combined with exercise improves pain in the short term and promotes increased internal knee extension moments when compared to exercise alone (Barton, Balachandar, et al., 2014). This highlights that tailored patellar taping may be beneficial to improving exercise therapy outcomes in the early stages of rehabilitation, as well as providing symptomatic pain relief. Therefore, we recommend that the tailored approach be used where possible, and the patient taught the optimal approach for them.

\subsubsection{Foot orthoses}

Broadly, there are two forms of foot orthoses to consider for people with PFP; prefabricated and custom moulded devices. Both can be modified to tailor prescription specific to the individual, for example adding medial/lateral wedging and/or heel lifts. At present, research tends to focus on inexpensive prefabricated foot orthoses, often modified to optimise patient comfort (Collins et al., 2008; Mills, Blanch, \& Vicenzino, 2012). Based on current 
evidence, this prescription approach is effective at reducing pain and improving outcomes in the short term (6 weeks) when compared to a wait and see or sham device (Barton, Munteanu, Menz, \& Crossley, 2010; Collins et al., 2008; Hossain, Alexander, Burls, \& Jobanputra, 2011; Mills, Blanch, Dev, Martin, \& Vicenzino, 2012). Importantly, the number needed to treat ranges between two and four (Collins et al., 2008; Mills, Blanch, Dev, et al., 2012). With an absence of evidence to suggest more expensive custom moulded foot orthoses will improve outcomes compared to prefabricated devices in PFP (Collins et al., 2012), we recommend using prefabricated devices, unless there is another clinical reason (e.g. foot deformity) to indicate the need for a custom moulded device.

Considering not all people with PFP will benefit from foot orthoses prescription, research has sought to identify those most likely to benefit (Barton, Menz, \& Crossley, 2011a, 2011b; Mills, Blanch, Dev, et al., 2012; Sutlive et al., 2004; Vicenzino, Collins, Cleland, \& McPoil, 2010). Based on a biomechanical theoretical paradigm outlined above (Fig. 3), foot orthoses have traditionally been thought to benefit those with excessive foot pronation the most. However, evidence related to the foot pronation biomechanical paradigm is inconsistent. Specifically, static foot posture has been reported not to relate to greater chance of success with foot orthoses (Barton et al., 2011a; Vicenzino et al., 2010). Studies evaluating the ability of foot mobility to predict outcomes have reported inconsistent findings also, including no association (Barton et al., 2011a), as well as greater mobility (Mills, Blanch, Dev, et al., 2012; Mills, Blanch et al., 2012; Vicenzino et al., 2010) and less mobility (Sutlive et al., 2004) related to success. Considering this, we do not recommend foot orthoses be prescribed on the basis of foot posture or foot mobility in isolation.

Dynamic foot function evaluation may provide greater insight into identifying those most likely to benefit from foot orthoses, with Barton et al. (Barton et al., 2011) reporting greater peak rearfoot eversion during walking predicted foot orthoses success in people with PFP. Additionally, coupling between greater peak rearfoot eversion, increased tibial internal rotation, and greater hip adduction during walking has been reported in people with PFP (Barton et al., 2012). A limitation to applying this research to clinical practice, however, is that it is based on three-dimensional motion analysis, a tool rarely available to the clinician and a measure of foot motion that is not accurately quantified using two-dimensional video analysis (Meyer, Falbriard, Aminian, \& Millet, 2018).

Given that the mechanisms of effect for distal intervention has not been clearly identified, further research is needed in this area. Beyond foot posture and function, other clinically applicable assessments, including treatment direction testing, may be considered by the clinician when determining likely success of foot orthoses prescription for PFP (Vicenzino, 2004). Additionally, higher functional index scores (Lack, Barton, Vicenzino, \& Morrissey, 2014), immediate improvements in functional performance (e.g. reduced pain during single legged squat) and patient's footwear assessed to be less supportive have been reported to be associated with greater likelihood of success (Barton et al., 2011a).

\subsubsection{Other options}

There is currently no evidence to suggest that any other passive adjunct treatments offer value in improving patient outcomes beyond 6 weeks when compared to a control or placebo condition. Based on a lack of supporting evidence from a currently limited body of research, the most recent consensus statement from the International Patellofemoral Research Retreat on physical interventions recommended that patellofemoral, knee and lumbar mobilisations may not improve outcomes (Crossley, Stefanik, et al., 2016). Additionally, electrophyscial agents such as ultrasound are also unlikely to improve outcomes (Brosseau et al., 2013). Two weeks of patellar mobilisation compared to no intervention, did not improve outcomes (Collins et al., 2012), while stretching in isolation, outside of multimodal physiotherapy intervention, has not been investigated. Consequently, best practice guidelines suggest the use of patellar mobilisation only in the presence of hypomobility, and that methods to promote flexibility be used on tight structures alone, especially those laterally (Barton et al., 2015). Although blanket statements recommending not to use electrophysical agents and joint mobilisations (Crossley, Stefanik, et al., 2016) may not apply to all patients with PFP, it is unlikely that many patients would need or should be provided with these passive adjuncts, which frequently rely on the treating therapist to facilitate. In particular, they should not be prioritised over appropriate education and guidance with exercise therapy.

\subsection{Education}

Education is considered a vital component in the treatment of PFP by experts, despite an absence of research directly evaluating its efficacy (Barton et al., 2015). Education targets should include managing patient expectations, load management, weight management when appropriate, ensuring self-management, teaching the importance of adherence to exercise-therapy, and implementing strategies to address fear of movement. Recent data indicates $57 \%$ of people with PFP enrolled in a clinical trial report unfavourable outcomes 5-8 years later (Lankhorst et al., 2016), indicating complete resolution of symptoms may not always be possible. Importantly, emerging evidence has linked chronicity in PFP with a poorer prognosis (Collins et al., 2013; Collins, Crossley, \& Darnell, 2010). Therefore, managing patient expectations in relation to likely outcome, particularly in the short to medium term, is of huge importance. If there is potential for improvement in a patient's condition, they must understand the time and effort required to complete appropriate rehabilitation and behaviour change (e.g. load management). This will be impacted on by the chronicity, current symptoms and irritability, and the associated deficits of the individual patient.

Load management education to modify PFJ loading may include appropriate activity modification, movement pattern modification and training and exercise therapy to increase the capacity to handle exposure to load. Technologies, including smart phone applications and activity measuring 'wearables', provide an easily utilised objective method to analyse baseline levels of activity and determine the magnitude of change following specific interventions. A detailed description and evaluation of all available devices is beyond the scope of this Masterclass, and the interested reader is referred to Willy, 2018 Masterclass (Willy, 2018). The objectivity afforded from data obtained from wearable technologies may assist to maximise adherence and facilitate the patient's reflection on the load magnitude of provocative activities. The clinician may also use this data to assist in guiding the patients return to activity guided by progression rates that are appropriate to the individual and their symptoms (calculators are provided at http://patellofemoral. trekeducation.org/).

Weight management through diet and exercise has been reported to be an effective intervention for knee osteoarthritis (Messier et al., 2013). Although similar evaluation does not exist in PFP, Hart et al.'s (Hart, Barton, Khan, Riel, \& Crossley, 2017) recent systematic review highlighted greater body mass index (BMI) in people with PFP, indicating similar weight management strategies may be beneficial in some patients. Regardless of symptomatic benefits, improved weight management in people with PFP may assist management of other health related issues such as cardiovascular disease, diabetes, and other physical and psychological impairments. 
Although the majority of previous research has focused on physical features of PFP, the importance of non-physical features is becoming more understood in recent research (Maclachlan et al., 2017). Clinicians are encouraged to consider non-physical features potentially influencing PFP during assessment, employing appropriate education strategies to inform the patient of the role that these characteristics can have on symptom severity and persistence (additional resources at http://patellofemoral.trekeducation.org/).

\section{Conclusion}

This clinical masterclass presents a synthesis of the current evidence relating to PFP symptom development, persistence, assessment and management. It highlights that structural, biomechanical, volume and psychological factors that can contribute to an individual's symptoms in differing amounts. Clinically reasoned paradigms have been described to integrate these features into a deficit focused, individually tailored, rehabilitation plan. The clinician is encouraged to consistently remain patient centred, incorporating shared decision-making strategies to construct the most effective treatment strategy for the patient in front of them. It is imperative that we consider patient's beliefs and expectations, whilst providing evidence informed interventions including exercise therapy, movement retraining, load management, treatment adjuncts and education to optimise patient adherence to the programme.

\section{Ethical approval}

None.

\section{Funding statement}

\section{No funding.}

\section{Conflict of interest}

None.

\section{References}

American College of Sports, M. (2009). American College of Sports Medicine position stand. Progression models in resistance training for healthy adults. Medicine \& Science in Sports \& Exercise, 41, 687-708.

Arendt-Nielsen, L., Skou, S. T., Nielsen, T. A., \& Petersen, K. K. (2015). Altered central sensitization and pain modulation in the CNS in chronic joint pain. Current Osteoporosis Reports, 13, 225-234.

Baker, A. D. (2014). Abnormal magnetic-resonance scans of the lumbar spine in asymptomatic subjects. A prospective investigation. In Classic papers in orthopaedics (pp. 245-247). Springer.

Baquie, P., \& Brukner, P. (1997). Injuries presenting to an Australian sports medicine centre: A 12-month study. Clinical Journal of Sport Medicine : Official Journal of the Canadian Academy of Sport Medicine, 7, 28-31.

Barton, C., Balachandar, V., Lack, S., \& Morrissey, D. (2014). Patellar taping for patellofemoral pain: A systematic review and meta-analysis to evaluate clinical outcomes and biomechanical mechanisms. British Journal of Sports Medicine, 48, $417-424$.

Barton, C. J., Bonanno, D., Levinger, P., \& Menz, H. B. (2010). Foot and ankle characteristics in patellofemoral pain syndrome: A case control and reliability study. Journal of Orthopaedic \& Sports Physical Therapy, 40, 286-296.

Barton, C., \& Crossley, K. (2016). Sharing decision-making between patient and clinician: The next step in evidence-based practice for patellofemoral pain?. In BMJ publishing group Ltd and British association of sport and exercise medicine.

Barton, C. J., Lack, S., Hemmings, S., Tufail, S., \& Morrissey, D. (2015). The 'best practice guide to conservative management of patellofemoral pain': Incorporating level 1 evidence with expert clinical reasoning. British Journal of Sports Medicine, 49, 923-934.

Barton, C. J., Levinger, P., Crossley, K. M., Webster, K. E., \& Menz, H. B. (2011). Relationships between the Foot Posture Index and foot kinematics during gait in individuals with and without patellofemoral pain syndrome. Journal of Foot and Ankle Research, 4, 10.

Barton, C. J., Levinger, P., Crossley, K. M., Webster, K. E., \& Menz, H. B. (2012). The relationship between rearfoot, tibial and hip kinematics in individuals with patellofemoral pain syndrome. Clin Biomech (Bristol, Avon), 27, 702-705.

Barton, C. J., Levinger, P., Webster, K. E., \& Menz, H. B. (2011). Walking kinematics in individuals with patellofemoral pain syndrome: A case-control study. Gait \& Posture, 33, 286-291.

Barton, C. J., Menz, H. B., \& Crossley, K. M. (2011a). Clinical predictors of foot orthoses efficacy in individuals with patellofemoral pain. Medicine \& Science in Sports \& Exercise, 43, 1603-1610.

Barton, C. J., Menz, H. B., \& Crossley, K. M. (2011b). The immediate effects of foot orthoses on functional performance in individuals with patellofemoral pain syndrome. British Journal of Sports Medicine, 45, 193-197.

Barton, C. J., Menz, H. B., Levinger, P., Webster, K. E., \& Crossley, K. M. (2011). Greater peak rearfoot eversion predicts foot orthoses efficacy in individuals with patellofemoral pain syndrome. British Journal of Sports Medicine, 45, 697-701.

Barton, C. J., Munteanu, S. E., Menz, H. B., \& Crossley, K. M. (2010b). The efficacy of foot orthoses in the treatment of individuals with patellofemoral pain syndrome: A systematic review. Sports Medicine, 40, 377-395.

Barton, C. J., \& Rathleff, M. S. (2016). 'Managing my patellofemoral pain': The creation of an education leaflet for patients. BMJ open sport \& exercise medicine, 2. e000086.

Boling, M. C., Padua, D. A., Marshall, S. W., Guskiewicz, K., Pyne, S., \& Beutler, A. (2009). A prospective investigation of biomechanical risk factors for patellofemoral pain syndrome the joint undertaking to monitor and prevent ACL injury (JUMP-ACL) cohort. The American Journal of Sports Medicine, 37, 2108-2116.

Bonacci, J., Hall, M., Saunders, N., \& Vicenzino, B. (2018). Gait retraining versus foot orthoses for patellofemoral pain: A pilot randomised clinical trial. Journal of Science and Medicine in Sport, 21(5), 457-461.

Brosseau, L., Casimiro, L., Welch, V., Milne, S., Shea, B., Judd, M., et al. (2013). Therapeutic ultrasound for treating patellofemoral pain syndrome. The Cochrane Library.

Cherkin, D. C., Anderson, M. L., Sherman, K. J., Balderson, B. H., Cook, A. J. Hansen, K. E., et al. (2017). Two-year follow-up of a randomized clinical trial of mindfulness-based stress reduction vs cognitive behavioral therapy or usual care for chronic low back pain. Journal of the American Medical Association : The Journal of the American Medical Association, 317, 642-644.

Collins, N. J., Bierma-Zeinstra, S. M., Crossley, K. M., van Linschoten, R. L. Vicenzino, B., et al. (2013). Prognostic factors for patellofemoral pain: A multicentre observational analysis. British Journal of Sports Medicine, 47, 227-233.

Collins, N. J., Bisset, L. M., Crossley, K. M., \& Vicenzino, B. (2012). Efficacy of nonsurgical interventions for anterior knee pain: Systematic review and metaanalysis of randomized trials. Sports Medicine, 42, 31-49.

Collins, N., Crossley, K., Beller, E., Darnell, R., McPoil, T., \& Vicenzino, B. (2008). Foot orthoses and physiotherapy in the treatment of patellofemoral pain syndrome: Randomised clinical trial. BMJ, 337, a1735.

Collins, N. J., Crossley, K. M., \& Darnell, R. (2010). Predictors of short and long term outcome in patellofemoral pain syndrome: A prospective longitudinal study. BMC Musculoskeletal Disorders, 11.

Collins, N. J., Vicenzino, B., van der Heijden, R. A., \& van Middelkoop, M. (2016). Pain during prolonged sitting is a common problem in persons with patellofemoral pain. Journal of Orthopaedic \& Sports Physical Therapy, 1-19.

Cowan, S. M., Bennell, K. L., Crossley, K. M., Hodges, P. W., \& McConnell, J. (2002). Physical therapy alters recruitment of the vasti in patellofemoral pain syndrome. Medicine \& Science in Sports \& Exercise, 34, 1879-1885.

Crossley, K. M., Cowan, S. M., Bennell, K. L., \& McConnell, J. (2004). Knee flexion during stair ambulation is altered in individuals with patellofemoral pain. Journal of Orthopaedic Research, 22, 267-274.

Crossley, K. M., Stefanik, J. J., Selfe, J., Collins, N. J., Davis, I. S., Powers, C. M., et al. (2016). 2016 Patellofemoral pain consensus statement from the 4th International Patellofemoral Pain Research Retreat, Manchester. Part 1: Terminology, definitions, clinical examination, natural history, patellofemoral osteoarthritis and patient-reported outcome measures. British Journal of Sports Medicine, 50, 839-843.

Crossley, K. M., Zhang, W.-J., Schache, A. G., Bryant, A., \& Cowan, S. M. (2011). Performance on the single-leg squat task indicates hip abductor muscle function. The American Journal of Sports Medicine, 39, 866-873.

Doménech, J., Sanchis-Alfonso, V., \& Espejo, B. (2014). Changes in catastrophizing and kinesiophobia are predictive of changes in disability and pain after treatment in patients with anterior knee pain. Knee Surgery, Sports Traumatology, Arthroscopy, 22, 2295-2300.

Domenech, J., Sanchis-Alfonso, V., López, L., \& Espejo, B. (2013). Influence of kinesiophobia and catastrophizing on pain and disability in anterior knee pain patients. Knee Surgery, Sports Traumatology, Arthroscopy, 21, 1562-1568.

Dowling, G. J., Murley, G. S., Munteanu, S. E., Smith, M. M., Neal, B. S., Griffiths, I. B., et al. (2014). Dynamic foot function as a risk factor for lower limb overuse injury: A systematic review. Journal of Foot and Ankle Research, 7, 53.

Duvigneaud, N., Bernard, E., Stevens, V., Witvrouw, E., \& Van Tiggelen, D. (2008) Isokinetic assessment of patellofemoral pain syndrome: A prospective study in female recruits. Isokinetics and Exercise Science, 16, 213-219.

Dye, S. F. (2005). The pathophysiology of patellofemoral pain: A tissue homeostasis perspective. Clinical Orthopaedics and Related Research, 100-110.

Dye, S. F., Stäubli, H. U., Biedert, R. M., \& Vaupel, G. L. (1999). The mosaic of pathophysiologycausing patellofemoral pain: Therapeutic implications. Operative Techniques in Sports Medicine, 7, 46-54.

Earl, J. E., \& Hoch, A. Z. (2011). A proximal strengthening program improves pain, function, and biomechanics in women with patellofemoral pain syndrome. The 
American Journal of Sports Medicine, 39, 154-163.

Esculier, J. F., Bouyer, L. J., Dubois, B., Fremont, P., Moore, L., McFadyen, B., et al. (2018). Is combining gait retraining or an exercise programme with education better than education alone in treating runners with patellofemoral pain?A randomised clinical trial. British Journal of Sports Medicine, 52, 659-666.

Farrokhi, S., Keyak, J. H., \& Powers, C. M. (2011). Individuals with patellofemoral pain exhibit greater patellofemoral joint stress: A finite element analysis study. Osteoarthritis and Cartilage, 19, 287-294.

Ferber, R., Kendall, D., \& Farr, L. (2011). Changes in knee biomechanics after a hipabductor strengthening protocol for runners with patellofemoral pain syndrome. Journal of Athletic Training, 46, 142-150.

Ferrari, D., Briani, R. V., de Oliveira Silva, D., Pazzinatto, M. F., Ferreira, A. S., Alves, N., et al. (2018). Higher pain level and lower functional capacity are associated with the number of altered kinematics in women with patellofemoral pain. Gait \& Posture, 60, 268-272.

Fox, A., Ferber, R., Saunders, N., Osis, S., \& Bonacci, J. (2017). Gait kinematics in individuals with acute and chronic patellofemoral pain. Medicine \& Science in Sports \& Exercise. https://doi.org/10.1249/mss.0000000000001465. PMID: 29077638.

French, D. J., France, C. R., Vigneau, F., French, J. A., \& Evans, R. T. (2007). Fear of movement/(re) injury in chronic pain: A psychometric assessment of the original English version of the Tampa scale for kinesiophobia (TSK). Pain, 127, $42-51$.

Fukuda, T. Y., Melo, W. P., Zaffalon, B. M., Rossetto, F. M., Magalhaes, E., Bryk, F. F., et al. (2012). Hip posterolateral musculature strengthening in sedentary women with patellofemoral pain syndrome: A randomized controlled clinical trial with 1-year follow-up. Journal of Orthopaedic \& Sports Physical Therapy, 42, 823-830.

Fulkerson, J. P. (1983). The etiology of patellofemoral pain in young, active patients: A prospective study. Clinical Orthopaedics and Related Research, 129-133.

Gabbett, T. J., Kennelly, S., Sheehan, J., Hawkins, R., Milsom, J., King, E., et al. (2016). If overuse injury is a 'training load error', should undertraining be viewed the same way? British Journal of Sports Medicine, 50, 1017-1018.

Gifford, L. S., \& Butler, D. S. (1997). The integration of pain sciences into clinical practice. Journal of Hand Therapy, 10, 86-95.

Giles, L. S., Webster, K. E., McClelland, J. A., \& Cook, J. (2013). Does quadriceps atrophy exist in individuals with patellofemoral pain? A systematic literature review with meta-analysis. Journal of Orthopaedic \& Sports Physical Therapy, 43, $766-776$.

Glaviano, N. R., \& Saliba, S. (2016). Impairment based rehabilitation for patellofemoral pain patients. The Physician and Sportsmedicine, 44, 311-323.

Hart, H. F., Barton, C. J., Khan, K. M., Riel, H., \& Crossley, K. M. (2017). Is body mass index associated with patellofemoral pain and patellofemoral osteoarthritis? A systematic review and meta-regression and analysis. British Journal of Sports Medicine, 51, 781-790.

Hazneci, B., Yildiz, Y., Sekir, U., Aydin, T., \& Kalyon, T. A. (2005). Efficacy of isokinetic exercise on joint position sense and muscle strength in patellofemoral pain syndrome. American Journal of Physical Medicine \& Rehabilitation, 84, 521-527.

van der Heijden, R. A., Lankhorst, N. E., van Linschoten, R., Bierma-Zeinstra, S. M., \& van Middelkoop, M. (2015). Exercise for treating patellofemoral pain syndrome. Cochrane Database of Systematic Reviews, 1. Cd010387.

van der Heijden, R. A., Oei, E. H., Bron, E. E., van Tiel, J., van Veldhoven, P. L. et al. (2016). No difference on quantitative magnetic resonance imaging in patellofemoral cartilage composition between patients with patellofemoral pain and healthy controls. The American Journal of Sports Medicine, 44, 1172-1178.

Herbst, K. A., Barber Foss, K. D., Fader, L., Hewett, T. E., Witvrouw, E., Stanfield, D., et al. (2015). Hip strength is greater in athletes who subsequently develop patellofemoral pain. The American Journal of Sports Medicine, 43, 2747-2752.

Ho, K. Y., Hu, H. H., Colletti, P. M., \& Powers, C. M. (2014). Recreational runners with patellofemoral pain exhibit elevated patella water content. Magnetic Resonance in Imaging, 32, 965-968.

Holden, S., Rathleff, M. S., Jensen, M. B., \& Barton, C. J. (2017). How can we implement exercise therapy for patellofemoral pain if we don't know what was prescribed? A systematic review. British Journal of Sports Medicine, Bjsports, 2017-097547.

Hossain, M., Alexander, P., Burls, A., \& Jobanputra, P. (2011). In Foot orthoses for patellofemoral pain in adults - art. no. CD008402 (1 ed., p. 8402). WILEY BLACKWELL. COMMERCE PLACE, 350 MAIN ST, MALDEN 02148, MA USA.

Jensen, M. C., Brant-Zawadzki, M. N., Obuchowski, N., Modic, M. T., Malkasian, D., \& Ross, J. S. (1994). Magnetic resonance imaging of the lumbar spine in people without back pain. New England Journal of Medicine, 331, 69-73.

Johnston, M., Pollard, B., \& Hennessey, P. (2000). Construct validation of the hospital anxiety and depression scale with clinical populations. Journal of Psychosomatic Research, 48, 579-584.

Kannus, P., Aho, H., Jarvinen, M., \& Niittymaki, S. (1987). Computerized recording of visits to an outpatient sports clinic. The American Journal of Sports Medicine, 15, 79-85.

Kettunen, J. A., Harilainen, A., Sandelin, J., Schlenzka, D., Hietaniemi, K., Seitsalo, S., et al. (2007). Knee arthroscopy and exercise versus exercise only for chronic patellofemoral pain syndrome: A randomized controlled trial. BMC Medicine, 5, 38.

Kettunen, J. A., Harilainen, A., Sandelin, J., Schlenzka, D., Hietaniemi, K., Seitsalo, S., et al. (2012). Knee arthroscopy and exercise versus exercise only for chronic patellofemoral pain syndrome: 5-year follow-up. British Journal of Sports Medicine, 46, 243-246.

Khayambashi, K., Mohammadkhani, Z., Ghaznavi, K., Lyle, M. A., \& Powers, C. M.
(2012). The effects of isolated hip abductor and external rotator muscle strengthening on pain, health status, and hip strength in females with patellofemoral pain: A randomized controlled trial. Journal of Orthopaedic \& Sports Physical Therapy, 42, 22-29.

Lack, S., Barton, C., Sohan, O., Crossley, K., \& Morrissey, D. (2015). Proximal muscle rehabilitation is effective for patellofemoral pain: A systematic review with meta-analysis. British Journal of Sports Medicine, 49, 1365-1376.

Lack, S., Barton, C., Vicenzino, B., \& Morrissey, D. (2014). Outcome predictors for conservative patellofemoral pain management: A systematic review and metaanalysis. Sports Medicine, 22(12), 1703-1716.

Lankhorst, N. E., Bierma-Zeinstra, S. M., \& van Middelkoop, M. (2012). Risk factors for patellofemoral pain syndrome: A systematic review. Journal of Orthopaedic \& Sports Physical Therapy, 42, 81-94.

Lankhorst, N. E., Bierma-Zeinstra, S. M., \& van Middelkoop, M. (2013). Factors associated with patellofemoral pain syndrome: A systematic review. British Journal of Sports Medicine, 47, 193-206.

Lankhorst, N. E., van Middelkoop, M., Crossley, K. M., Bierma-Zeinstra, S. M., Oei, E. H., Vicenzino, B., et al. (2016). Factors that predict a poor outcome 5-8 years after the diagnosis of patellofemoral pain: A multicentre observational analysis. British Journal of Sports Medicine, 50, 881-886.

Lee, G. V., \& Barnett, B. G. (1994). Using reflective questioning to promote collaborative dialogue. Journal of Staff Development, 15, 16-21.

Lee, T. Q., Morris, G., \& Csintalan, R. P. (2003). The influence of tibial and femoral rotation on patellofemoral contact area and pressure. Journal of Orthopaedic \& Sports Physical Therapy, 33, 686-693.

Linton, S. J., \& Boersma, K. (2003). Early identification of patients at risk of developing a persistent back problem: The predictive validity of the Orebro musculoskeletal pain questionnaire. The Clinical Journal of Pain, 19, 80-86.

Maclachlan, L. R., Collins, N. J., Matthews, M. L., Hodges, P. W., \& Vicenzino, B. (2017). The psychological features of patellofemoral pain: A systematic review. British Journal of Sports Medicine, 51, 732-742.

Maclachlan, L. R., Matthews, M., Hodges, P. W., Collins, N. J., \& Vicenzino, B. (2018). The psychological features of patellofemoral pain: A cross-sectional study. Scandinavian Journal of Pain, 18(2), 261-271.

McConnell, J. (1996). Management of patellofemoral problems. Manual Therapy, 1, 60-66.

McPoil, T. G., \& Cornwall, M. W. (1996). The relationship between static lower extremity measurements and rearfoot motion during walking. Journal of Orthopaedic \& Sports Physical Therapy, 24, 309-314.

Messier, S. P., Mihalko, S. L., Legault, C., Miller, G. D., Nicklas, B. J., DeVita, P., et al. (2013). Effects of intensive diet and exercise on knee joint loads, inflammation, and clinical outcomes among overweight and obese adults with knee osteoarthritis: The IDEA randomized clinical trial. Journal of the American Medical Association: The Journal of the American Medical Association, 310, 1263-1273.

Meyer, F., Falbriard, M., Aminian, K., \& Millet, G. P. (2018). How accurate is visual determination of foot strike pattern and pronation assessment. Gait \& Posture, 60, 200-202.

Mills, K., Blanch, P., Dev, P. Martin, M., \& Vicenzino, B. (2012). A randomised control trial of short term efficacy of in-shoe foot orthoses compared with a wait and see policy for anterior knee pain and the role of foot mobility. British Journal of Sports Medicine, 46, 247-252.

Mills, K., Blanch, P., \& Vicenzino, B. (2012). Comfort and midfoot mobility rather than orthosis hardness or contouring influence their immediate effects on lower limb function in patients with anterior knee pain. Clinical Biomechanics, 27, 202-208.

Murray, N. B., Gabbett, T. J., \& Townshend, A. D. (2016). Relationship between preseason training load and in-season availability in elite Australian Football players. International Journal of Sports Physiology and Performance, 1-21.

Myer, G. D., Ford, K. R., Barber Foss, K. D., Goodman, A., Ceasar, A., et al. (2010). The incidence and potential pathomechanics of patellofemoral pain in female athletes. Clinical Biomechanics, 25, 700-707.

Neal, B. S., Barton, C. J., Gallie, R., O'Halloran, P., \& Morrissey, D. (2016). Runners with patellofemoral pain have altered biomechanics which targeted interventions can modify: A systematic review and meta-analysis. Gait \& Posture, 45, 69-82.

Neal, B. S., Griffiths, I. B., Dowling, G. J., Murley, G. S., Munteanu, S. E., Franettovich Smith, M. M., et al. (2014). Foot posture as a risk factor for lower limb overuse injury: A systematic review and meta-analysis. Journal of Foot and Ankle Research, 7, 55.

Nimon, G., Murray, D., Sandow, M., \& Goodfellow, J. (1998). Natural history of anterior knee pain: A 14- to 20-year follow-up of nonoperative management. Journal of Pediatric Orthopaedics, 18, 118-122.

Noehren, B., Hamill, J., \& Davis, I. (2013). Prospective evidence for a hip etiology in patellofemoral pain. Medicine \& Science in Sports \& Exercise, 45, 1120-1124.

Noehren, B., Pohl, M. B., Sanchez, Z., Cunningham, T., \& Lattermann, C. (2012). Proximal and distal kinematics in female runners with patellofemoral pain. Clinical Biomechanics, 27, 366-371.

Noehren, B., Scholz, J., \& Davis, I. (2011). The effect of real-time gait retraining on hip kinematics, pain and function in subjects with patellofemoral pain syndrome. British Journal of Sports Medicine, 45, 691-696.

Nunes, G. S., Barton, C. J., \& Serrão, F. V. (2017). Hip rate of force development and strength are impaired in females with patellofemoral pain without signs of altered gluteus medius and maximus morphology. Journal of Science and Medicine in Sport.

Nunes, S., Stapait, E. L., Kirsten, M. H., Noronha, M. d., \& Santos, G. M. (2013). Clinical test for diagnosis of patellofemoral pain syndrome: Systematic review with 
meta-analysis. Physical Therapy in Sport, 14(1), 54-59.

O'Sullivan, P. (2005). Diagnosis and classification of chronic low back pain disorders: Maladaptive movement and motor control impairments as underlying mechanism. Manual Therapy, 10, 242-255.

de Oliveira Silva, D., Barton, C. J., Pazzinatto, M. F., Briani, R. V., \& de Azevedo, F. M, (2016). Proximal mechanics during stair ascent are more discriminate of females with patellofemoral pain than distal mechanics. Clin Biomech (Bristol, Avon), 35, 56-61.

de Oliveira Silva, D., Briani, R. V., Pazzinatto, M. F., Ferrari, D., Aragão, F. A., de Albuquerque, C. E., et al. (2015). Reliability and differentiation capability of dynamic and static kinematic measurements of rearfoot eversion in patellofemoral pain. Clinical Biomechanics, 30, 144-148.

de Oliveira Silva, D., Briani, R. V., Pazzinatto, M. F., Ferrari, D., Aragão, F. A., \& de Azevedo, F. M. (2015). Reduced knee flexion is a possible cause of increased loading rates in individuals with patellofemoral pain. Clinical Biomechanics, 30 , 971-975.

Østerås, B., Østerås, H., Torstensen, T. A., \& Vasseljen, O. (2013). Dose-response effects of medical exercise therapy in patients with patellofemoral pain syndrome: A randomised controlled clinical trial. Physiotherapy, 99, 126-131.

Pazzinatto, M. F., de Oliveira Silva, D., Barton, C., Rathleff, M. S., Briani, R. V., de Azevedo, et al. (2016). Female adults with patellofemoral pain are characterized by widespread hyperalgesia, which is not affected immediately by patellofemoral joint loading. Pain Medicine, 17(10), 1953-1961.

Pazzinatto, M. F., de Oliveira Silva, D., Pradela, J., Coura, M. B., Barton, C., de Azevedo, et al. (2017). Local and widespread hyperalgesia in female runners with patellofemoral pain are influenced by running volume. Journal of Science and Medicine in Sport, 20, 362-367.

Powers, C. M. (2003). The influence of altered lower-extremity kinematics on patellofemoral joint dysfunction: A theoretical perspective. Journal of Orthopaedic \& Sports Physical Therapy, 33, 639-646.

Powers, C. M. (2010). The influence of abnormal hip mechanics on knee injury: A biomechanical perspective. Journal of Orthopaedic \& Sports Physical Therapy, 40, $42-51$.

Powers, C. M., Bolgla, L. A., Callaghan, M. J., Collins, N., \& Sheehan, F. T. (2012). Patellofemoral pain: Proximal, distal, and local factors, 2nd international research Retreat. Journal of Orthopaedic \& Sports Physical Therapy, 42, A1-A54.

Powers, C. M., Chen, P.-Y., Reischl, S. F., \& Perry, J. (2002). Comparison of foot pronation and lower extremity rotation in persons with and without patellofemoral pain. Foot \& Ankle International, 23, 634-640.

Ramskov, D., Barton, C., Nielsen, R. O., \& Rasmussen, S. (2015). High eccentric hip abduction strength reduces the risk of developing patellofemoral pain among novice runners initiating a self-structured running program: A 1-year observational study. Journal of Orthopaedic \& Sports Physical Therapy, 45, 153-161.

Rathleff, C. R., Baird, W. N., Olesen, J. L., Roos, E. M., Rasmussen, S., \& Rathleff, M. S. (2013a). Hip and knee strength is not affected in 12-16 year old adolescents with patellofemoral pain-a cross-sectional population-based study. PLoS One, 8, e79153.

Rathleff, M. S., Petersen, K. K., Arendt-Nielsen, L., Thorborg, K., \& Graven-Nielsen, T. (2015). Impaired conditioned pain modulation in young female adults with long-standing patellofemoral pain: A single blinded cross-sectional study. Pain Medicine, 17(5), 980-988.

Rathleff, M. S., Rathleff, C. R., Crossley, K. M., \& Barton, C. J. (2014). Is hip strength a risk factor for patellofemoral pain? A systematic review and meta-analysis. British Journal of Sports Medicine, 48, 1088.

Rathleff, M. S., Rathleff, C. R., Olesen, J. L., Rasmussen, S., \& Roos, E. M. (2016). Is knee pain during adolescence a self-limiting condition? Prognosis of patellofemoral pain and other types of knee pain. The American Journal of Sports Medicine, 44, 1165-1171.

Rathleff, M. S., Roos, E. M., Olesen, J. L., \& Rasmussen, S. (2015b). Exercise during school hours when added to patient education improves outcome for 2 years in adolescent patellofemoral pain: A cluster randomised trial. British Journal of Sports Medicine, 49, 406-412.

Rathleff, M. S., Roos, E. M., Olesen, J. L., Rasmussen, S., \& Arendt-Nielsen, L. (2013b). Lower mechanical pressure pain thresholds in female adolescents with patellofemoral pain syndrome. Journal of Orthopaedic \& Sports Physical Therapy, 43, $414-421$.

Rodrigues, P., TenBroek, T., \& Hamill, J. (2013). Runners with anterior knee pain use a greater percentage of their available pronation range of motion. Journal of Applied Biomechanics, 29, 141-146.

Roper, J. L., Harding, E. M., Doerfler, D., Dexter, J. G., Kravitz, L., Dufek, J. S., et al. (2016). The effects of gait retraining in runners with patellofemoral pain: A randomized trial. Clin Biomech (Bristol, Avon), 35, 14-22.

Sale, D. G. (1988). Neural adaptation to resistance training. Medicine \& Science in Sports \& Exercise, 20, S135-S145.

Salsich, G. B., Brechter, J. H., \& Powers, C. M. (2001). Lower extremity kinetics during stair ambulation in patients with and without patellofemoral pain. Clinical Biomechanics, 16, 906-912.

Sanchis-Alfonso, V., Rosello-Sastre, E., Monteagudo-Castro, C., \& Esquerdo, J. (1998). Quantitative analysis of nerve changes in the lateral retinaculum in patients with isolated symptomatic patellofemoral malalignment. A preliminary study. The American Journal of Sports Medicine, 26, 703-709.

Schoots, E. J., Tak, I. J., Veenstra, B. J., Krebbers, Y. M., \& Bax, J. G. (2013). Ultrasound characteristics of the lateral retinaculum in 10 patients with patellofemoral pain syndrome compared to healthy controls. Journal of Bodywork and Movement Therapies, 17, 523-529.

Sheerin, K. R., Hume, P. A., \& Whatman, C. (2012). Effects of a lower limb functional exercise programme aimed at minimising knee valgus angle on running kinematics in youth athletes. Physical Therapy in Sport, 13, 250-254.

Smith, B. E., Selfe, J., Thacker, D., Hendrick, P., Bateman, M., Moffatt, F., et al. (2018) Incidence and prevalence of patellofemoral pain: A systematic review and meta-analysis. PLoS One, 13. e0190892.

Stefanik, J. J., Neogi, T., Niu, J., Roemer, F. W., Segal, N. A., Lewis, C. E., et al. (2014), The diagnostic performance of anterior knee pain and activity-related pain in identifying knees with structural damage in the patellofemoral joint: The multicenter osteoarthritis study. Journal of Rheumatology, 41, 1695-1702.

Sutlive, T. G., Mitchell, S. D., Maxfield, S. N., McLean, C. L., Neumann, J. C. Swiecki, C. R., et al. (2004). Identification of individuals with patellofemora pain whose symptoms improved after a combined program of foot orthosis use and modified activity: A preliminary investigation. Physical Therapy, 84, 49-61.

Swinkels-Meewisse, E., Swinkels, R., Verbeek, A., Vlaeyen, J., \& Oostendorp, R. (2003). Psychometric properties of the Tampa Scale for kinesiophobia and the fear-avoidance beliefs questionnaire in acute low back pain. Manual Therapy, 8 , 29-36.

Taunton, J. E., Ryan, M. B., Clement, D. B., McKenzie, D. C., Lloyd-Smith, D. R., \& Zumbo, B. D. (2002). A retrospective case-control analysis of 2002 running injuries. British Journal of Sports Medicine, 36, 95-101.

Thijs, Y., De Clercq, D., Roosen, P., \& Witvrouw, E. (2008). Gait-related intrinsic risk factors for patellofemoral pain in novice recreational runners. British Journal of Sports Medicine, 42, 466-471.

Thijs, Y., Van Tiggelen, D., Roosen, P., De Clercq, D., \& Witvrouw, E. (2007) A prospective study on gait-related intrinsic risk factors for patellofemoral pain. Clinical Journal of Sport Medicine : Official Journal of the Canadian Academy of Sport Medicine, 17, 437-445.

Tiberio, D. (1987). The effect of excessive subtalar joint pronation on patellofemoral mechanics: A theoretical model. Journal of Orthopaedic \& Sports Physical Therapy, 9, 160-165.

Toigo, M., \& Boutellier, U. (2006). New fundamental resistance exercise determinants of molecular and cellular muscle adaptations. European Journal of Applied Physiology, 97, 643-663.

Van Tiggelen, D., Cowan, S., Coorevits, P., Duvigneaud, N., \& Witvrouw, E. (2009). Delayed vastus medialis obliquus to vastus lateralis onset timing contributes to the development of patellofemoral pain in previously healthy men: A prospective study. The American Journal of Sports Medicine, 37, 1099-1105.

Vicenzino, B. (2004). Foot orthotics in the treatment of lower limb conditions: A musculoskeletal physiotherapy perspective. Manual Therapy, 9, 185-196.

Vicenzino, B., Collins, N., Cleland, J., \& McPoil, T. (2010). A clinical prediction rule for identifying patients with patellofemoral pain who are likely to benefit from foot orthoses: A preliminary determination. British Journal of Sports Medicine, 44, 862-866.

Whatman, C., Hing, W., \& Hume, P. (2011). Kinematics during lower extremity functional screening tests Are they reliable and related to jogging? Physical Therapy in Sport, 12, 22-29.

Whatman, C., Hing, W., \& Hume, P. (2012). Physiotherapist agreement when visually rating movement quality during lower extremity functional screening tests. Physical Therapy in Sport, 13, 87-96.

Willy, R. W. (2018). Innovations and pitfalls in the use of wearable devices in the prevention and rehabilitation of running related injuries. Physical Therapy in Sport, 29, 26-33.

Willy, R. W., \& Davis, I. S. (2011). The effect of a hip-strengthening program on mechanics during running and during a single-leg squat. Journal of Orthopaedic \& Sports Physical Therapy, 41, 625-632.

Willy, R. W., Manal, K. T., Witvrouw, E. E., \& Davis, I. S. (2012). Are mechanics different between male and female runners with patellofemoral pain? Medicine \& Science in Sports \& Exercise, 44, 2165-2171.

Willy, R. W., Scholz, J. P., \& Davis, I. S. (2012). Mirror gait retraining for the treatment of patellofemoral pain in female runners. Clinical Biomechanics, 27, 1045-1051.

Windt, J., Gabbett, T. J., Ferris, D., \& Khan, K. M. (2017). Training load-injury paradox: Is greater preseason participation associated with lower in-season injury risk in elite rugby league players? British Journal of Sports Medicine, 51, 645-650.

Witvrouw, E., Callaghan, M. J., Stefanik, J. J., Noehren, B., Bazett-Jones, D. M., Willson, J. D., et al. (2014). Patellofemoral pain: Consensus statement from the 3rd international patellofemoral pain research Retreat held in Vancouver, September 2013. British Journal of Sports Medicine, 48, 411-414.

Witvrouw, E., Cambier, D., Danneels, L., Bellemans, J., Werner, S., Almqvist, F., et al. (2003). The effect of exercise regimens on reflex response time of the vasti muscles in patients with anterior knee pain: A prospective randomized intervention study. Scandinavian Journal of Medicine \& Science in Sports, 13, 251-258.

Witvrouw, E., Danneels, L., Van Tiggelen, D., Willems, T. M., \& Cambier, D. (2004) Open versus closed kinetic chain exercises in patellofemoral pain: A 5-year prospective randomized study. The American Journal of Sports Medicine, 32, $1122-1130$.

Wouters, I., Almonroeder, T., DeJarlais, B., Laack, A., Willson, J. D., \& Kernozek, T. W. (2012). Effects of a movement training program on hip and knee joint frontal plane running mechanics. International journal of sports physical therapy, 7, 637. 